\title{
Bush II y la crisis del multilateralismo
}

\author{
FRANCISCO JAVIER IBISATE \\ Departamento de Economía \\ Universidad Centroamericana (UCA) \\ San Salvador
}

RESUMEN: La victoria electoral del Partido Republicano en las elecciones presidenciales de 2004, no solamente abre las puertas a un segundo mandato del presidente George W. Bush, sino también a la consolidación de la política unilateralista que caracterizó a la primera administración del gobernante estadounidense. Una segunda "Era Bush" en la Casa Blanca supone la profundización de la politica belicista de los EEUU, amparada bajo la bandera de la lucha antiterrorista, así como el abondamiento de la crisis de los organismos creados para consensuar politicas a escala global.

\section{El voto de Osama Bin Laden}

El candidato demócrata John Kerry aceptó el resultado de las urnas y, de acuerdo a una democrática tradición, felicitó al reelecto George W. Bush. Como era de temer, unas elecciones libres no han dado el mejor resultado, ni para los residentes en Estados Unidos, ni para el entorno mundial. No es broma decir que las elecciones del pasado mes de noviembre las ha ganado Osama Bin Laden. El 29 de octubre, cuatro días antes de las elecciones, Osama Bin Laden aparece 
en las pantallas de la televisión advirtiendo al pueblo norteamericano con nuevas represalias y atentados "contra los que amenazan nuestra seguridad". Esta repentina aparición cambia la naturaleza de estas elecciones. "Es un referéndum sobre George Bush y su manejo de la guerra en Irak. ¿Cuál debe ser ahora la estrategia contra el terrorismo y cuál de los dos candidatos es el más calificado para aplicarla"?

¿A qué candidato puede favorecer esta intervención de Bin Laden? "Los comentaristas tienden a decir: George Bush, porque el vídeo coloca el 11 de septiembre en el centro del debate. Pero al mismo tiempo, agregan, el vídeo recuerda a los electores que, pese a todos los duros discursos del pasado, el Jefe de $\mathrm{Al}$ Qaeda sigue en pie. Se puede razonar en uno o en otro sentido, pero lo que Bin Laden quiere ante todo es la audiencia y ha escogido el mejor momento". ("Osama Bin Laden irrumpe en la campaña americana". Le Monde, 3 de noviembre de 2004) Esto significa que lo que la administración Bush ha generado durante cuatro años en el pueblo norteamericano es la inseguridad ante un terrorismo que él ha alimentado con su equivocada guerra contra Irak. Sirva como botón de muestra que en plena campaña presidencial George W. Bush, junto con W. Putin, han lanzado su campaña de 'la guerra sin fin contra el terrorismo internacional', ("La guerra sin fin, un error". ECA, octubre de 2004; pp. 1027-1044)

La gran equivocación de esa escasa mayoría que votó a favor de George W. Bush es que espera que este mesiánico presidente le libere, vía el control policíaco, de ese ambiente de inseguridad que les aflige desde hace cuatro años, cuando ni la persona ni su estrategia son los más acertados a tal fin. Aunque no sea la razón principal, el mismo discurso y las razones expresadas en este vídeo por Bin Laden aconsejaban desplazar a la dinastía Bush. Elegir a George W. Bush era optar por la 'inseguridad duradera'.

He aquí algunos pasajes del vídeo: "Pueblo estadounidense: estas son mis reflexiones sobre las causas y los resultados (de los ataques del 11 de septiembre) y sobre la manera correcta de evitar otro Manhattan. Les digo que la seguridad es un pilar importante de la vida humana. Los hombres libres nunca renuncian a su seguridad, contrariamente a lo que alega George Bush, que nosotros detestamos la libertad. Que nos explique Bush por qué nosotros nunca hemos atacado a Suecia, por ejemplo. Es evidente que quienes detestan la libertad no están dotados de almas nobles como las de aquellos dieci- 
nueve (autores de los atentados del 11 septiembre) Dios guarde sus almas".

"Si nosotros les combatimos es porque somos libres, no cerramos los ojos a los valores; nosotros queremos devolver la libertad a nuestra nación. De la misma manera que ustedes atentan contra nuestra seguridad, nosotros atentamos contra la suya. No les entiendo. Aunque han pasado cuatro años (luego del 11 de septiembre) Bush mantiene el embrollo, les engaña y les oculta la verdadera razón. Permanecen las razones para que se repita el pasado. Les voy a explicar las razones de aquellos sucesos y el momento en que se tomó la decisión (de realizar los ataques del 11 septiembre) para que ustedes reflexionen. Juro que nosotros nunca habíamos tenido la idea de atacar las torres; pero cuando la gota de agua desbordó el vaso, al ver la injusticia y la arbitraria alianza estadounidense-israelí contra nuestros hermanos en Palestina y en el Líbano, entonces le idea me vino al espíritu. Los sucesos que me han conmocionado de forma más directa remontan a 1982 cuando Norteamérica dio luz verde a los israelitas para que invadieran Líbano, con la ayuda de la sexta flota norteamericana".

"En el momento en que vi destruidas las torres del Líbano me vino la idea de aplicar el mismo castigo a la injusticia y que las torres de los Estados Unidos fueran destruidas para que ese país pruebe un poco de lo que nosotros aguantamos y que Estados Unidos deje de matar a nuestros hijos y mujeres. No hemos encontrado mayor dificultad en comportarnos con Bush y su administración, dada la semejanza con los regímenes de nuestros países, donde la mitad es dominada por los militares y la otra mitad por los hijos de reyes y de presidentes, con los que tenemos una larga experiencia. Estas dos partes cuentan con muchas personas conocidas por su arrogancia, su avaricia y su expoliación del dinero. Este parentesco comenzó luego de las visitas a la región de Bush padre. Pero, mientras que algunos de los dirigentes árabes, deslumbrados por América, esperaban que estas visitas influyeran sobre nuestros países, resulta que fue él, Bush padre, quien se contagió con los regímenes monárquicos y militares, sintiendo envidia de verles permanecer en el poder durante décadas, robando impunemente los dineros públicos. Él, Bush, ha transmitido la tiranía y la represión de las libertades a su hijo. Ellos, los dirigentes norteamericanos, le llaman ley nacional, Patriot Act, bajo el pretexto 
de combatir el terrorismo. Vuestra seguridad no está en las manos ni de John Kerry, ni de George Bush, ni de Al Qaeda. Vuestra seguridad está en vuestras manos. Todo mandato presidencial que no dañe nuestra seguridad, asegurará automáticamente la suya" (Verbatim. "Permanecen las razones para que se repita el pasado". Le Monde, 3 de noviembre de 2004)

Si el público norteamericano tuvo la oportunidad de ver y escuchar en sus pantallas este discurso de Bin Laden y su deseo era buscar la mayor seguridad para todos los conciudadanos la alternativa más adecuada hubiera sido John Kerry, porque "su mandato presidencial" no hubiera sido tan unilateral, nacional e internacionalmente, como lo había demostrado y lo sigue demostrando el reelecto presidente Bush. Los datos con que contamos preanuncian un largo combate entre George W. Bush y Osama Bin Laden, es decir, la inseguridad duradera. Bush apuesta por la línea dura, confirmando a Donald Rumsfeld al frente del Pentágono, sustituye a Colin Powell por Condoleeza Rice y en el Foro de Cooperación Económica Asia-Pacífico, aboga por avanzar en el combate contra el terrorismo internacional.

Llegados a final de año Osama Bin Laden aparece en una nueva cinta de audio instando a los iraquíes a boicotear las elecciones previstas para el mes de enero. En conferencia de prensa, 20 diciembre 2004, Bush afirma que las elecciones tendrán lugar en la fecha asignada del 30 de enero y "que los terroristas no lograrán descarrilar el proceso". Con fecha 28 de diciembre, los sunitas anuncian su retiro de los comicios, si no se acepta prorrogar la fecha anunciada dada la situación de inseguridad en el país. Colin Powell trata de animar a los sunitas para que se unan a este esfuerzo, dando un 'no al terrorismo' y 'un sí a la democracia'. Osama Bin Laden revela dos cosas. Que Al Zarquai es su emir representante en Irak, a quien deben escuchar todos los musulmanes. Además, se anuncia la inseguridad electoral: "Para el Islam esta constitución es infiel y, en consecuencia, todos los que participen en estas elecciones serán considerados infieles. Tengan cuidado de los secuaces que hablan en nombre de los partidos islámicos y grupos que instan a la gente a participar en esta evidente apostasía". La amenaza parece dirigirse sobre todo a algunos de los clérigos chiitas. (La Prensa Gráfica, 28 de diciembre 2004; p. 32)

$\mathrm{Si}$ a estas amenazas le agregamos las que hiciera el número dos de Al Qaeda, Ayman Al-Zaouahri, el 29 de noviembre, estamos ante la 
inseguridad duradera. "Ustedes (los norteamericanos) deben saber que nosotros somos la nación de la paciencia y de la perseverancia. Nosotros perseveramos en nuestro combate contra ustedes hasta el final de los tiempos. El resultado de las elecciones no es importante para nosotros. Voten por quien quieran votar: Bush, Kerry o el mismo diablo. Lo que nos interesa es purgar nuestro país de todos los agresores. Tengo un último consejo para Norteamérica y se lo debo dar: ustedes deben escoger entre dos maneras de comportarse con los musulmanes; o bien ustedes se comportan en base al respeto de los intereses comunes, o bien ustedes se comportan como si ellos fueran presas fáciles". ("El número 2 de Al Qaeda promete llevar adelante su combate contra Estados Unidos". Le Monde, 30 noviembre de 2004)

Este es el eco de aquellas palabras de George W. Bush, en que presentaba la campaña de Irak como una guerra contra los hombres sin fe y sin ley. "Mi fe me sostiene porque yo oro cada día. Pido que ella me dé sabiduría y fuerza. Yo oro por la paz. Yo oro por la paz". (Le Monde, 3 de marzo de 2003) Realmente una escasa mayoría ha votado a favor de una mala herencia, Bush II.

\section{Condolencias a la minoría demócrata}

Como dice Ignacio Ramonet, de Le Monde Diplomatique, la reelección de George W. Bush "constituye una grave afrenta moral infligida al espíritu de la democracia estadounidense, la más antigua del mundo y, en tanto tal, referencia primordial. Claro que esta vez no hay nada que objetar. Nadie puede discutir el carácter legítimo del escrutinio. Y confirma que la democracia —el menos imperfecto de los regímenes políticos - no está protegida contra opciones que pueden llevar al poder a peligrosos demagogos. En efecto, es preocupante que Bush, conocido por su fundamentalismo religioso, su mediocridad intelectual y su incultura, haya sido el candidato más votado de la historia electoral estadounidense".

Ignacio Ramonet cita a continuación una serie de hechos y datos, conocidos incluso fuera de los Estados Unidos, y que hacen más incomprensible el resultado de esta elección. "Tanto más cuanto que ha engañado a su pueblo y mentido al Congreso para conseguir la autorización para librar una 'guerra preventiva' (no autorizada por la ONU) e invadir a Irak; ha alentado un uso desproporcionado de la fuerza y 
provocado la muerte de millares de civiles iraquíes inocentes; ha ignorado la 'orden ejecutiva' de 1976 del presidente Gerald Ford (que sigue vigente y prohibe a los servicios secretos el asesinato de dirigentes extranjeros) y ordenado la ejecución de supuestos 'terroristas'; ha violado la práctica de la tortura en la cárcel de Abu Ghraib y en otros centros secretos de detención; y ha despertado el espíritu del macartismo que consiste en considerar culpable al ciudadano sospechoso de tener vínculos con una organización enemiga.

Con tan siniestro historial, otro dirigente hubiera sido declarado persona non grata y excluido del mundo civilizado. No ha sucedido esto con George W. Bush, quien por añadidura, y como presidente de la única superpotencia mundial, ocupa el lugar central del dispositivo político internacional". Ramonet afirma que su segundo mandato se anuncia como una continuación del primero, luego de la elección de Alberto González para el Ministerio de Justicia, y de Condoleeza Rice para el Departamento de Estado, a lo que se añadirá la confirmación de Donald Rumsfeld al frente del Pentágono. El artículo concluye con esta pregunta: "Terminará también Bush por admitir que los aspectos negativos de la mundialización (pobreza agravada de los pobres, injusticias planetarias, rivalidades regionales, desarreglos climáticos, etc.) pueden degenerar en enfrentamientos si no se les opone una concertación multilateral? ("Bush II". Periodistadigital.com; 2 de diciembre 2004)

Una forma de transmitir nuestras condolencias a personas representativas del ala demócrata es recordar algunas de sus reflexiones sobre la conducta moral de la administración Bush, como un preámbulo de lo que será su segunda era y como una explicación de esta desafortunada elección. Arthur Schlesinger, asesor del presidente John F. Kennedy, escribía una carta a sus amigos europeos con el mensaje de "No perdáis la esperanza". El epicentro del mensaje es la guerra de Irak. "La doctrina de Bush es atacar a un enemigo unilateralmente si hace falta, antes de que pueda atacarnos, un derecho reservado a Estados Unidos. Esto convierte a este país en el juez, el jurado y el verdugo del mundo, una posición difícilmente popular... Mientras tanto, la ansiedad por la seguridad interior se mantiene en muchos hogares estadounidenses. Los habitantes de la era del terrorismo están dispuestos a pagar un precio por proteger a sus familias. Como todas las guerras, la de Irak ha aumentado el poder presidencial. Hoy la presi- 
dencia imperial ha renacido en Washington. La denominada Ley Patriótica, presentada apresuradamente tras el 11 septiembre por un fiscal general imperial, impone restricciones a las libertades civiles de los ciudadanos estadounidenses. El tribunal supremo ha condenado la suspensión presidencial del juicio justo para los presos retenidos muchos meses y sin acceso a abogado defensor en Guantánamo".

"El gobierno de Bush es el más secretista que se recuerda y su secretismo aumenta de día en día. El fiscal general ha hecho todo lo posible por sabotear la Ley sobre la Libertad de Información. El número de documentos clasificados ha aumentado un $60 \%$ entre 2001 y 2003. Dichas restricciones preocupan a los estadounidenses... Las encuestas de opinión pública dan a entender que el $45 \%$ del electorado adora a Bush y otro $45 \%$ lo detesta. No es probable que muchos electores de los dos bandos opuestos cambien de idea de aquí a las elecciones del 2 de noviembre. La batalla la ganará el 10\% de los indecisos. Inmediatamente después del 11 septiembre, una oleada de simpatía mundial inundó Estados Unidos. Tres años después el mundo lo contempla con hostilidad. Nunca en su historia el país había sido tan impopular en el extranjero. Eso no se les pasa por alto al votante estadounidense". (El País, 12 de septiembre 2004). Esta carta de Schlesinger nos asoma al misterio de ese $45 \%$ de la sociedad norteamericana para quienes George W. Bush es un ídolo. Esto es tema de preocupación y de tristeza, porque ese $45 \%$ no es una sociedad moralmente desarrollada.

Similar es el tono de la carta que Norman Birbaum, profesor emérito de Georgetown, dirigiera a ocho primeros ministros europeos que apoyaron la guerra de Irak. En esta carta se acusa la falta de moralidad de ocho jefes de Estado (de Berlusconi a Aznar) que apoyan la guerra contra Irak, desoyendo las masivas manifestaciones antibelicistas en todas sus grandes ciudades. De paso se nos hacen ver las divisiones transatlánticas que generó la guerra preventiva contra Irak. "Los sondeos de opinión en Estados Unidos reflejan una nación profundamente dividida. La consternación, la duda y la oposición a la guerra contra Irak están aumentando con rapidez... Los preparativos del Gobierno Bush para la guerra incluyen restricciones draconianas para los derechos de los residentes o visitantes árabes o musulmanes en Estados Unidos. Quienes respaldan al presidente han organizado una campaña de difamación e intimidación contra aquellos ciudada- 
nos que manifiesten su disensión. El plan milenarista del Gobierno Bush para democratizar al Oriente Próximo nunca se ha debatido en el Congreso ni en la nación".

"Declaran ustedes que el sistema de derecho es un componente primordial de nuestra herencia común. El presidente Bush sostiene que nuestro país tiene derecho a eliminar a enemigos en potencia mediante ataques preventivos. La proclamación del derecho de ataque preventivo por parte de una nación contra otra es un asalto definitivo contra la dolorosamente construida estructura del Derecho Internacional. Es una invitación a que otros países sigan su ejemplo. Estados Unidos ya ha transgredido el derecho internacional con el trato dado a los prisioneros que ha hecho en Afganistán o que han sido capturados por gobiernos aliados en otras partes... Aceptan ustedes, con pasmosa tranquilidad, la afirmación de que 'el régimen iraquí y sus armas de destrucción masiva representan una clara amenaza para la seguridad mundial'. Repiten algo que no es mas que una ficción de la Casa Blanca: que Irak respalda a Al Qaeda. No hay pruebas convincentes de ninguno de los dos argumentos. Tratan ustedes la obsesión del presidente Bush con Irak como algo racional”.

"Las amenazas para la seguridad mundial que supone la creciente brutalidad del gobierno israelí en Palestina, el conflicto entre la India y Pakistán, el programa de armamento nuclear de Corea del Norte, no parecen preocuparles excesivamente. Las amenazas mayores como el hambre, la enfermedad y la pobreza en el mundo no merecen una mención de su parte. Mientras tanto, con una indiferencia bastante convincente por las consecuencias, están ustedes dispuestos a respaldar a Estados Unidos en el inicio de una conflagración en Oriente Medio. Nada parece importarles más a ustedes que evitar un conflicto con el Gobierno actual de los Estados Unidos. Es difícil creer que esto vaya en consonancia con la dignidad de sus pueblos o con una duradera amistad con Estados Unidos. Lo que nos honraría a todos sería la abierta expresión de una disensión y no la ansiosa demostración de fidelidad. En este sentido las opiniones públicas de sus países son mejores amigas de nuestra nación que sus dirigentes”. (El País, 9 de febrero de 2003)

Seis meses antes, Norman Birbaum, como lo han hecho bastantes analistas, había cuestionado la moral empresarial de George W. Bush y Richard Cheney: "La economía está en recesión, la renta está estan- 
cada, el paro en alza. Las pruebas de delito de fraude, con un costo devastador para empleados y accionistas, proliferan en las esferas más altas del capitalismo estadounidense. La carrera del presidente y del vicepresidente como empresarios da pie para que se les formulen una serie de reproches o incluso abre el camino para un procesamiento. La mitad de la nación ha sufrido pérdidas en sus cuentas de acciones de interés variable y duda de su capacidad para pagar la universidad de sus hijos o para jubilarse decentemente. La desconfianza y el pesimismo han sustituido al optimismo de los noventa". ("EEUU: una oposición sin convicción”. El País, 31 de agosto de 2002)

La razón de introducir este breve testimonio es que por las mismas fechas otros autores afirman que la quiebra de la gran empresa Enron salpica a la Casa Blanca, siendo su presidente Ken Lay, cercano amigo de George W. Bush. Por ejemplo, Joaquín Estefanía, en un artículo "Las torres gemelas del capitalismo" cita a Paul Krugman: "Krugman ha escrito que el escándalo de la empresa Enron (contabilidad creativa para engañar a los ciudadanos en general, a los inversionistas y a sus trabajadores y jubilados) marcará un punto de inflexión mayor para la percepción que Estados Unidos tiene de sí mismo que los atentados del 11 de septiembre de 2001". (El País, 6 de septiembre de 002)

Paul Krugman es el autor del libro: "El gran resquebrajamiento", (Ed. Norma, Bogotá, 2004) que integra toda una secuencia de columnas escritas en el New York Times. "Este libro es, en primer lugar, una crónica de los años en que todo de nuevo fue malo... Porque ésta es, en buena parte, una historia sobre el liderazgo, el liderazgo increíblemente malo, en el sector privado y en los corredores del poder. $\mathrm{Y}$, en efecto, es una acusación a George W. Bush".(p.18) "Yo comencé a señalar la atroz deshonestidad de la administración Bush mucho antes que la mayoría de expertos". (p.27) "Estoy hablando de la derecha radical norteamericana - un movimiento que ahora controla efectivamente la Casa Blanca, el Congreso, buena parte de la rama judicial y una buena tajada de los medios de comunicación-. El dominio de ese movimiento lo cambia todo: ya no aplican las viejas reglas de la política y de las decisiones de política económica”.(p. 31) Paul Krugman teme que en la era Bush II siga reinando la deshonestidad económica. 
En la misma línea de la economía conviene trasladar nuestras condolencias a Joseph Stigltiz, quien avala su breve artículo "Cuatro años de fracasos de Bush" con el testimonio de otros economistas. "A finales de agosto firmé, junto con otros nueve Premios Nobel de Economía estadounidenses, una carta abierta a la opinión publica de los Estados Unidos. Es difícil conseguir que dos economistas -y mucho menos dos Premios Nobel - estén de acuerdo en nada. Sin embargo, en este caso, nuestra preocupación era tan grande que superamos todas nuestras discrepancias". Escribimos. "El presidente Bush y su administración han emprendido un rumbo irresponsable y extremista que pone en peligro la salud económica a largo plazo de nuestra nación. Las diferencias entre el presidente Bush y John Kerry a la hora de administrar la economía son mucho mayores que en cualquier otra elección presidencial que hayamos conocido. El presidente Bush cree que unos recortes fiscales que benefician a los estadounidenses más ricos son la respuesta para prácticamente cualquier problema económico. En ésta, como en otras cosas, Bush se equivoca por completo y es demasiado dogmático para reconocerlo". (El País, 8 de octubre de 2004), Estas mismas ideas, en forma más ordenada y razonada, las expone J. Stiglitz en su libro "Los felices 90. La semilla de la destrucción”. (Edit. Taurus, México, 2004)

\section{Nieblas sobre Irak.}

Tratando de buscar explicaciones al resultado irracional de estas elecciones puede ser iluminador el artículo de Alain Touraine, director del Instituto de Estudios Superiores de París, "Estados Unidos entre la barbarie y el derecho". El espíritu guerrero se ha apoderado de esa escasa mayoría de la sociedad norteamericana y ha tetanizado sus conciencias. “¿Hasta dónde proseguirá la caída moral y militar de Estados Unidos, que se considera el representante del bien y transformará este país en principal figura del eje del mal? Desde los primeros días, desde el primer debate en el Consejo de Seguridad, Estados Unidos se situó al margen de la ley. Lo que se decía por la mañana en la ONU, de manera poco convincente, era contradicho por lo que Bush decía unas horas mas tarde en Washington. Las mentiras sobre el armamento de Sadam Husein eran evidentes ya en la época, que pasé en Nueva York, en que se preparaba la guerra. Falso enemigo, falsa victoria, todo ha conducido al fracaso de la ocupación. Pero, por 
encima de todo, la cuestión de los prisioneros iraquíes, que llama la atención sobre el escándalo increíble de Guantánamo y que no se toleraría en una república bananera, ha llevado al ejército estadounidense a que sus soldados humillen y torturen a unos prisioneros de guerra".

"Nos gustaría pensar que la oleada de críticas aumentará a medida que se vayan conociendo nuevos documentos y que la caída de Bush no se podrá retener antes de las elecciones de noviembre, Sí, icómo nos gustaría admirar a unos EE.UU. en el que hay tantas personas e instituciones admirables! Pero sería dar muestras de excesivo optimismo. Es poco probable que la mayoría de la población se vuelva contra Bush y éste tiene todo el interés en cubrir a Rumsfeld. El espíritu guerrero domina hoy el imperio estadounidense y este espíritu ataca cada vez más violentamente las reglas del derecho, los procedimientos democráticos y el respeto de los grandes principios humanitarios. EEUU sólo conoce guerras a distancia y sólo reaccionó contra la guerra cuando los boys destinados en Vietnam murieron por una causa perdida. Pero en aquella época el enemigo seguía siendo el 'bando socialista', ya en declive. Hoy es un adversario nuevo, en pleno crecimiento, y los estadounidenses tardarán todavía mucho en convencerse de que deben aceptar una derrota, es decir, reconocer su impotencia para eliminar a su adversario... Seamos más pesimistas y más realistas. EEUU está involucrado en la guerra. Primero lo estuvo de forma indirecta al ser puramente tecnológica; ahora se hunde en esta guerra que se ha convertido en una guerra sucia y que amenaza con prolongarse" (El País, 20 de mayo 2004).

Al querer buscar explicaciones al resultado de las elecciones estadounidenses se estaría sumando el voto de quienes viven y apoyan el fundamentalismo mesiánico de que ha hecho repetida profesión George W. Bush: "La historia nos ha dado la oportunidad de defender la libertad y de combatir la tiranía y esto es lo que nuestro país hará. Tal vez algunos se cansarán. Otros, tal vez, se fatigarán ante nuestros esfuerzos por la libertad. No así yo, ni mi gobierno, ni nuestro país". (Le Monde, 9 de febrero 2002) Pero el fundamentalismo religioso de 'la colina de Washington' (para algunos, imagen del templo de Jerusalén) engendró la réplica de otro fundamentalismo tan radical.

En consonancia con las revelaciones hechas por Osama Bin Laden, Moisés Naim habla de la "guerra equivocada" de George W. Bush.

\section{9}

Bush II y la crisis del multilateralismo 
"En lugar de concentrar todas sus energías en luchar contra las extrañas y ágiles redes de civiles apátridas que perpetraron los atentados (del 11 septiembre) Estados Unidos reaccionó atacando dos países", primero Afganistán y luego Irak. "Así, enfrentado a la perspectiva de librar un nuevo tipo de guerra contra enemigos transnacionales, que operan en células pequeñas de civiles apátridas y que usan estrategias, armas y tácticas distintas a las de los manuales, el gobierno de Bush prefirió luchar contra un enemigo conocido, cuyo rostro y localización le eran más familiares. Muy pronto, sin embargo, las tropas estadounidenses descubrieron que su principal amenaza no era el ejército tradicional de Irak, que en otro garrafal error fue disuelto. Quienes los asesinaban eran lo que los abogados del Pentágono denominan ahora "combatientes ilegales": soldados con nacionalidades y motivos tan poco predecibles que hacen difícil entender quiénes son sus dirigentes, cuál es su cadena de mando, dónde están sus lealtades y qué les hace tan propensos a suicidarse por su causa. Esto no estaba en los manuales". (El País, 2 de agosto 2004) Este enemigo desconocido explica que los expertos hablen de una guerra perdida de antemano. Esto es lo que genera la sensación de inseguridad ciudadana, lo que se ha llamado la 'sobretasa Bin Laden', que, en forma equivocada, los electores piensan que puede ser mejor controlada con la línea dura de Donald Rumsfeld y G.W. Bush. De hecho se ha votado por la inseguridad duradera.

Sin olvidar las motivaciones económicas de la guerra contra Irak, confirmadas por P. Harris y J. Stiglitz, es oportuno recordar las reflexiones hechas por Bill Clinton al diario Le Monde. Los corresponsales del periódico francés preguntan: "La imagen de Norteamérica ha caído muy abajo en amplios sectores de la opinión mundial. ¿Le inquieta esto?". "Esto es tan importante como inquietante. Esto se explica en gran parte por el conflicto de Irak. Hemos atacado a Irak de forma apresurada cuando Hans Blix, jefe de inspectores de la ONU, no había terminado su tarea. También se ha tratado bruscamente a Francia y Alemania porque no estaban de acuerdo con nosotros. Yendo más a fondo, la impopularidad que sufre Estados Unidos se debe al unilateralismo repetido, desde la administración Bush; rechazo del tratado de no proliferación de armas nucleares, rechazo de la Corte Penal Internacional y oposición al protocolo de Kyoto, sobre el calentamiento de la tierra" 
"¿Diría usted que la ausencia de armas de destrucción masiva en Irak da la razón a la posición que Francia ha defendido?". "Los Estados Unidos rechazaron alargar tres o cuatro semanas el proceso de inspección que pedía Hans Blix. Hoy se sabe por qué. Al interior de la administración Bush había una escuela de pensamiento que imponía la guerra contra Irak por motivos que nada tenían que ver con las armas de destrucción masiva. Esta era la escuela de Paul Wolfowitz, número dos del Pentágono, y de los llamados neoconservadores. Norte América, según ellos, debía utilizar su poder para derribar la dictadura de Bagdad, facilitar el nacimiento de un movimiento de reformas en Oriente Próximo, que permitiría a su vez una solución más fácil del conflicto israelo-palestino. Esta gente no quería pasar por la ONU”. ("John Kerry puede esperar una fácil victoria". Le Monde, 21 de julio de 2004)

Repitiendo el unilateralismo de la administración Bush, esa escasa mayoría que lo apoya, víctima de la ansiedad por la seguridad interior, está dispuesta a pagar un precio por proteger a sus familias. La repetida publicidad de estar en el ojo del terrorismo alimenta el espíritu guerrero de esta mitad de la sociedad norteamericana, que disculpa y cierra los ojos ante el irrespeto de los acuerdos de Ginebra, las normas del derecho internacional y acata positivamente las nuevas medidas de la línea dura de George W. Bush.

\section{¿Un nuevo comienzo?}

Ese es el deseo de todos los jefes de Estado europeos que, contentos o contrariados con el resultado de las elecciones, han tenido que felicitar al presidente reelecto George W. Bush, procurando - al mismo tiempo- transmitir el mensaje de un nuevo comienzo, la restauración de la relación transatlántica gravemente afectada. "No podemos encontrar respuestas satisfactorias a tantos desafíos a que estamos hoy enfrentados sin una estrecha colaboración transatlántica", dijo Jacques Chirac en su mensaje a Bush. Así se expresó también su ministro de Asuntos Exteriores, M. Barnier: "Donde quiera haya crisis y guerras, no se podrá salir de esos agujeros negros sin la acción coordinada de Americanos y Europeos y, en el caso del Próximo Oriente, de los países árabes". Tanto el Jefe de Estado español, José Luis Zapatero (que retiró sus tropas de Irak), como el presidente alemán, Gerhard Schröder (que no las envió), han mostrado su deseo de co-

Bush Il y la crisis del multilateralismo 
operar con la administración norteamericana. "En esto se juega el interés de Estados Unidos, como el de Alemania y de Europa", dijo Gerhard Schröder.

Interesante ha sido el deseo de Tony Blair, manifestado a la Cámara de los Comunes, de exhortar a su aliado norteamericano a relanzar la dinámica de la paz en el Próximo Oriente, paso esencial a sus ojos para ganar la guerra contra el terrorismo. Para Tony Blair la reelección del presidente llega en un momento crítico, en un mundo "fracturado, dividido e incierto". "Europa y América, en particular, deben reanudar su alianza. Todos nosotros como dirigentes, y no sólo el presidente Bush, tenemos la responsabilidad de enfrentar este desafío; urge que lo hagamos".

Dato preanunciado, V. Putin, que recibía la visita de Silvio Berlusconi, manifestó su alegría porque el pueblo norteamericano no se dejó intimidar por el terrorismo. Putin ya había manifestado su deseo de que George W. Bush fuera reelecto el 2 de noviembre, y en Israel claramente se ha dicho que con Bush será más fácil llevar a término el plan de retiro de Gaza. Muchos comentarios de prensa desean que Washington ponga en práctica una política externa más respetuosa del multilateralismo. Los comentarios que llegan de África muestran el temor de que la guerra en Irak y la lucha contra el terrorismo desvíen por mucho tiempo la atención de los esfuerzos necesarios para ayudar al continente a salir de la pobreza, la miseria y los conflictos. El vicepresidente de Kenia, Moody Awory, expresó su temor - personal- de ver una América "dictatorial".

Este multilateralismo o estrecha colaboración transatlántica es tanto más necesaria porque la agenda internacional es amplia y cargada. En Irak se plantea ya el interrogante de la fecha de las elecciones, es decir, su seguridad interna, la representatividad de las mismas elecciones y el calendario del eventual retiro de las tropas de la coalición. En Irán, la Agencia Internacional de la Energía Atómica debe dejar constancia de que Teherán cesa toda actividad ligada al uranio enriquecido. Corea del Norte boicotea las conversaciones multilaterales sobre su programa nuclear. En el Próximo Oriente está pendiente todo el programa del retiro de Gaza, al mismo tiempo que el Consejo de Seguridad de la ONU ha pedido el retiro de las tropas sirias del Líbano y ayudar el gobierno de Nairobi, Sudán, a lograr una paz efectiva. 
En 2005 Londres preside las reuniones del G-8 y Tony Blair quiere impulsar la paz israelo-palestina y la ayuda al desarrollo, sin lo cual no habrá paz. En el año 2005 queda pendiente un problema nada sencillo: proseguir las negociaciones del ciclo de Doha, de la Organización Mundial del Comercio, cuyo acuerdo marco se había firmado en Ginebra el $1^{\circ}$ agosto de 2004, y que debe concluirse en Hong Kong en diciembre 2005. ("Los europeos, todos, dicen desear 'un nuevo comienzo". Le Monde, 4 de noviembre de 2004)

Dentro de sus fronteras George W. Bush no da muestras de iniciar un 'nuevo comienzo', si la palabra nuevo significa distinto. Más bien hay que decir 'de nuevo el mismo comienzo'. Una de las primeras nominaciones ha sido la de Alberto González para el ministerio de Justicia, sustituyendo a John Ashcroft, persona de triste moral y memoria, como se puede apreciar en la carta abierta de Norman Birbaum. Alberto González ha sido consejero jurídico del gobernador de Texas y le ha acompañado a George W. Bush a la Casa Blanca en 2001. Los defensores de los derechos del hombre reprochan a Alberto González por su participación en la política de Bush contra el terrorismo. De acuerdo a Human Rights, González habría declarado que la convención de Ginebra no se aplica a los prisioneros capturados en Afganistán y transferidos a Guantánamo. Estos prisioneros, calificados como "enemigos combatientes" no serían sometidos a la justicia norteamericana ni extranjera. También se le acusa de haber creado los tribunales militares ("military order") para juzgar a los prisioneros de "la guerra contra el terrorismo". "George Bush nombra a una persona de confianza para el ministerio de justicia”. Le Monde, 11 de noviembre de 2004) Graduado de Harvard, parece haber alcanzado una 'maestría' en violación de los derechos humanos.

Tampoco la nominación de Condoleeza Rice, sustituyendo a Colin Powell en el cargo de Secretario de Estado, ha sido bien visto por diplomáticos europeos, por cuanto puede hacer más difíciles las relaciones con Washington. La forma de expresarse de estos diplomáticos es lamentar, con pena, el retiro de un hombre moderado. El diario Le Monde recoge los testimonios de los ministros de Asuntos Exteriores de Francia, del representante de la Unión Europea, Javier Solana, del ministro alemán Joschka Fischer, de Silvio Berlusconi, de Ana Palacio de España y de Tony Blair. Casi todos hacen mención de las tensiones derivadas de la guerra de Irak, al mismo tiempo que resaltan su 
apertura al diálogo, a trabajar juntos en temas difíciles y a generar una sensación de amistad. ("Europa ve partir con pena a un hombre moderado". Le Monde, 17 de noviembre de 2004) Este panegírico no nos hace olvidar que Colin Powell mintió descaradamente al presentar ante el Consejo de Seguridad de la ONU pruebas falsas sobre la presencia de armas de destrucción masiva en Irak, para legitimar su guerra preventiva.

Los corresponsales de Le Monde ven en la nominación de Condoleeza Rice a la Secretaría de Estado una mayor coherencia de la Casa Blanca, es decir, una persona cercana y fiel al presidente, dado que ella ha sido su consejera de seguridad. "En los cuatro años pasados, yo me he apoyado en sus consejos, beneficiándome de su gran experiencia y apreciando su discernimiento sereno y equilibrado. Ahora me siento honrado de que haya aceptado servir en mi gabinete". Los comentaristas dicen que Condoleeza Rice es un estilo muy diferente del Secretario saliente. Lo que más puede iluminar su conducta futura es la presentación que nos hace el mismo Bush. "Después de que sea confirmada por el Senado, Condoleeza Rice iniciará sus funciones en un momento crítico para nuestro país. Nosotros somos una nación en guerra. Dirigimos una importante coalición contra un enemigo determinado. Aplicamos nuevas técnicas e instituciones para enfrentar a regímenes fuera de ley, para oponernos a la proliferación de armas y de productos peligrosos y para quebrar las redes terroristas... Los Estados Unidos han respondido a la llamada de la historia para ayudar a las fuerzas de la reforma y de la libertad en el Gran Medio Oriente, para que esta región pueda desarrollarse con esperanza más que con cólera... Seguimos un nuevo camino para resolver el conflicto israelo-árabe, una visión que toma en cuenta las aspiraciones pacíficas de los palestinos en el cuadro de un Estado democrático buscando también la seguridad de nuestros amigos israelitas”... Por su parte el Washington Post comenta que este cambio en la dirección de la diplomacia "traduce el triunfo de una concepción más confrontativa de la diplomacia, propia del vicepresidente Cheney y del Secretario de Defensa Donald Rumsfeld". ("El nombramiento de Condoleeza Rice confirma el conservadurismo de la administración Bush". Le Monde, 16 de noviembre de 2004)

Más críticas y oposición ha generado la permanencia de Donald Rumsfeld en el cargo de Secretario de Defensa. Rumsfeld tiene una 
larga historia política: embajador ante la OTAN (1973-74); secretario general de la Casa Blanca con Gerald Ford (1974-75); secretario de Defensa (1975-77) Antes de esas fechas hay una anécdota interesante: "Me parece que Rumsfeld no va a durar mucho. Vamos a deshacernos de él", dijo el presidente Nixon en 1971. En aquel tiempo Rumsfeld era un problema en el sentido contrario al actual: Nixon no soportaba que su asesor criticase la presencia de Estados Unidos en Vietnam y abogara por la salida inmediata de las tropas. La anécdota está recogida en el libro de James Mann, Rise of vulcans: The history of Bush's War Cabinet. Nixon nunca llegó a destituir a su asesor díscolo.("Rumsfeld resiste". El País, 26 de diciembre 2004)

Su problema, según algunos analistas, está en su propio talante, ese carácter que Bush definió hace unos días como "tosco y brusco", que lo confirman con una serie de respuestas y anécdotas. Según Javier del Pino, corresponsal de El País en Washington, hay senadores y congresistas de su propio partido que piden la dimisión inmediata, "con la situación en Irak convertida en una pesadilla y con el personal militar indignado por la falta de equipamiento y planificación". Sin embargo, 'Rummy' goza del apoyo de Bush, porque está haciendo "un trabajo excelente". ("Bush apuesta por la línea dura en política exterior con un segundo mandato de Rumsfeld”. El Pais, 4 de diciembre 2004)

Entre otros, Rumsfeld tiene dos agujeros negros: las torturas en la prisión iraquí de Abu Ghraib (y otras), y más recientemente los bombardeos y crímenes en la ciudad santa y arrasada de Faluya. A partir de una escena que todos pudieron ver en la televisión se sospecha que, una vez más, los soldados están violando el derecho humanitario de la guerra. "La alta comisaria de la ONU para los derechos humanos, Louise Arbour, y Amnistía Internacional han lanzado la alarma ante posibles violaciones - por todas partes - de las convenciones que rigen la guerra. Ayer mismo, sin mediar explicación, el ejército estadounidense detuvo a Nasir Ayef, vicepresidente del Consejo Nacional Iraquí, que se había mostrado contrario a la ofensiva militar contra Faluya y cuyo Partido Islámico había anunciado su retirada del gobierno provisional de Alaui”. Así con estos métodos, EEUU no asegurará una paz mínima que cree unas mínimas condiciones aceptables para las elecciones previstas en 27 de enero. En Faluya, EEUU ha demostrado que sigue empecinado en su gran error: creer que la 
fuerza militar lo puede todo". ("El crimen de Faluya". El País, 17 de diciembre 2004) De momento no hay signos de un nuevo comienzo, ni de una apertura al multilateralismo.

\section{En 2005 se pondrá de moda el "terrorismo"}

¿Cómo encontrar una vía intermedia que dé respuesta a dos realidades opuestas? Las siguientes reflexiones se hacen pocos días después de la masacre perpetrada por terroristas chechenos (agravada por la incuria de los agentes rusos) en la escuela de Beslan, Rusia. "El terrorismo internacional existe, es algo muy real. Golpea aquí y allí de manera ignominiosa. Emplea medios que dejan sin legitimidad la causa invocada. Es verdad que el islamismo radical inspira a diversos grupos terroristas, usen o no la consigna genérica de $\mathrm{Al}$ Qaeda. Es necesario acorralar solidariamente esas redes, desmantelar su estructura y perseguir a sus inspiradores. Es algo necesario; una misión de la policía en verdadera cooperación internacional, sobre todo euro-norteamericana". Palabras tomadas de una editorial de Le Monde, 10 de septiembre 2004. Trasladábamos también una reflexión del ministro de Asuntos Exteriores francés, Hubert Védrine, presente en el foro de Davos en Nueva York, enero 2002: "Estamos amenazados hoy día por el nuevo simplismo de reducir todos los problemas del mundo a la simple lucha contra el terrorismo. Esto no es serio y no se puede aceptar esta idea. Si no estamos de acuerdo con la política norteamericana debemos decirlo. Podemos y debemos decirlo". (ECA, 2002, p.66) Reducir todos los problemas del mundo a la categoría de "terrorismo mundial" es un gran simplismo, por cuanto "es más fácil lanzar un eslogan que formular una política”, que ofrezca una respuesta a estos problemas, incluido el terrorismo. ("La guerra sin fin, un error." $E C A$, 2004; p. 1028)

A finales de 2004 , en varias reuniones y en forma reiterada aparece el fantasma que nos acorrala y que se expresa como lucha contra el terrorismo, en sus diversas modalidades. Con la inseguridad cunde el miedo. "La lucha contra la proliferación de armas de destrucción masiva se hace más difícil, según la CIA". La "bomba sucia" (de materiales radioactivos) está al alcance de $\mathrm{Al}$ Qaeda. A partir de documentos hallados en Afganistán en el verano de 2002, de acuerdo a la Agencia Central de Inteligencia, la red Bin Laden dispondría de los medios rudimentarios para fabricar el gas mostaza o similares y que está inte- 
resada en la fabricación de la bomba sucia. "Está a su alcance la fabricación de la bomba sucia; los materiales radiactivos necesarios a su fabricación son relativamente fáciles de obtener de fuentes industriales y de laboratorios médicos". Al Qaeda realiza investigaciones con agentes biológicos y se concentra en el ántrax para un ataque masivo, aunque el grupo tratará de producir y utilizar otros agentes biológicos en ataques de menor escala.

La CIA insiste en que cada vez es más fácil obtener los elementos para la producción de armas de destrucción masiva. "Dado que las tecnologías aplicadas a las armas nucleares, biológicas, químicas y a los misiles balísticos son cada vez más accesibles a nivel mundial, también aparecen nuevas fuentes de aprovisionamiento, que hacen más difícil los esfuerzos realizados para controlar su proliferación". Esta creciente accesibilidad hace que "técnicamente" un Estado que quisiera dotarse del arma nuclear "tiene la posibilidad de producir el material fisible y de militarizarlo", dice la Agencia. Por lo tanto la CIA aconseja controlar a los abastecedores de los insumos peligrosos. Asegura también que Irán "prosigue vigorosamente su investigación para producir armas nucleares, químicas y biológicas”. (Le Monde, 25 de noviembre 2004)

Imaginamos que este informe de la CIA goce de mayor credibilidad que el falso informe presentado en octubre 2002 al Congreso para probar la existencia de armas de destrucción masiva en Irak. (ECA 2004, p. 1034) Quince días más tarde se reúnen en París los ministros de Salud del Grupo de los Siete (G-7) más México, para organizar "la lucha contra el bioterrorismo y las pandemias". La pandemia de gripe que ahora amenaza pudiera generar hasta cien millones de muertos en el mundo. "La amenaza de una pandemia (epidemia en gran escala) es $\tan$ temible como un ataque bioterrorista e igualmente probable. Se trate de algo natural o malintencionado, es necesario poder reaccionar. Ambos tipos de amenazas precisan de las mismas estrategias de respuesta". Se ha levantado también un inventario de las vacunas necesarias y disponibles. Además de los análisis de los posibles ataques biológicos y químicos se ha abordado en París al riesgo nuclear y radiológico, a partir de la fatal experiencia de Chernobyl, la central nuclear rusa. (Le Monde, 11 de diciembre de 2004)

Todas estas preocupaciones son razonables, porque son amenazas reales como la gripe aviaria. Sin embargo, llaman la atención dos co- 
sas: primero, que estas pandemias se unen a la amenaza del bioterrorismo y, segundo, que sea el G-7, más México, quien organiza la reunión y toma a tiempo las medidas preventivas o defensivas para defenderse de las pandemias naturales o malévolas. Si la preocupación tiene esa base humanitaria, la defensa de la vida de tantas personas, ¿por qué el G-7 sigue manteniendo una conducta tan distinta desde Doha-Qatar y Cancún, hasta nuestros días, cuando se trata de las pandemias reales del sida, la tuberculosis y la malaria, reacios a la apertura de los medicamentos genéricos?. ¿Por qué R. Zoellick dice que EEUU puede suspender su CAFTA si Guatemala sigue insistiendo en la disponibilidad estatal de los medicamentos genéricos? También es bioterrorismo imponer el derecho de propiedad intelectual por encima del derecho-deber de los Estados de proteger la saludvida de sus ciudadanos. Vuelta al simplismo de "terrorismo $=11$ Septiembre".

En el Foro de Cooperación Económica Asia-Pacífico, celebrado en Chile, el 20 de noviembre de 2004, "la lucha contra el terrorismo centra el inicio de la cumbre".(El País, 20 de noviembre de 2004) Si bien se quieren tratar temas importantes como sacar adelante la Ronda de Doha, sin embargo George W. Bush, con el nuevo vigor que le da su reelección, "acentúa la presión sobre Irán y Corea del Norte. George W. Bush busca la unidad en su lucha contra el terrorismo". (Le Monde, 20 de noviembre de 2004) Se trata de un foro que reúne a veintiún países distintos y diferentes como pueden serlo Australia con Brunei y Nueva Zelanda con Papúa-Nueva Guinea. Siendo distintos, "los 21 países del Foro Asia-Pacífico abogan por avanzar en el combate al terrorismo. Los terroristas fuera del sistema financiero". (El Pais, 21 de noviembre 2004)

En francés encontramos lo mismo: "El foro de la APEC termina bajo el signo de la seguridad". En realidad se están tocando dos modalidades de terrorismo, aunque sólo la primera lleva ese nombre. Los dirigentes del Foro quieren demostrar "su firme resolución de afrontar colectivamente la amenaza del terrorismo y sus consecuencias desastrosas para las poblaciones así como para las economías de la región". Los organizadores de la cumbre "acuerdan adoptar las medidas que impidan el acceso de los terroristas al sistema financiero internacional y al blanqueo de dinero". Se innovan pasaportes más seguros, así como hay que prevenir la introducción de materias tóxicas en la 
cadena alimenticia y adoptar sistemas de salud ante las amenazas sanitarias regionales, aunque no dicen quién o quiénes imponen las barreras sanitarias, fitosanitarias y bioterroristas. Para las economías del tercer mundo tiene mayor relevancia el tema del comercio que adquiere visos de terrorismo internacional.

Se trata de la importancia de "relanzar las negociaciones de la Organización Mundial del Comercio, que son nuestra primera prioridad en materia de liberalización del comercio mundial”. Se utiliza el acostumbrado lenguaje: nuestro objetivo es facilitar sustancialmente el acceso a los mercados de productos agrícolas, de bienes manufacturados y de servicios, "eliminando siempre los factores de distorsión, sobre todo las subvenciones a las exportaciones agrícolas”. Se agregan también dos temas: la lucha contra la corrupción y la lucha contra el sida.

En una de sus últimas intervenciones como Secretario de Estado, Colin Powell reitera sus acusaciones a Irán, sobre sus misiles nucleares, de la misma forma que algún representante de Irán se ha unido al coro de quienes piden que las tropas de Estados Unidos se retiren del país vecino. Se renueva la presión sobre Corea del Norte, lo cual nos indica que, después de Irak, el efecto dominó apunta a Irán y Corea del Norte. Un dato novedoso es que en este foro se han encontrado colateralmente George W. Bush y V. Putin que, el pasado mes de septiembre habían unificado sus políticas de lucha contra el terrorismo internacional. Bush habría pedido a Putin "que le proporcione su propia explicación sobre lo que está pasando en Rusia y sus razones" a raíz de las últimas reformas emprendidas en el país. (Le Monde, 21 de noviembre de 2004)

¿Cuáles son las reformas rusas que preocupan a la administración Bush? Se trata de dos reformas que tienen un origen común, la nostalgia de la "Gran Madre Rusia". La Federación Rusa ha dejado de ser la Unión Soviética, uno de los imperios del siglo XX. Rusia se queda con la mayor parte de la industria bélica, pero una economía, que de la recesión pasa al caos económico y donde los "nuevos zares" proceden a una apropiación desvergonzada de enormes empresas públicas (ejemplo, la petrolera Yokus), no puede prestar atención a la renovación y modernización de todo el equipo militar. Incapaz de modernizar a toda la tropa, V. Putin anuncia el fin de la penuria en el presupuesto militar 
para el área de los vectores y cabezas nucleares. Esta será una de las reformas, que no es mal vista por la administración Bush.

La otra reforma tiene más de diez años de prehistoria. La Federación Rusa ha soportado mal que algunas de las catorce repúblicas independientes —además de las naciones satélites- luego de 1991 discurran hacia el Occidente; la OTAN como pacto de seguridad y la Unión Europea como el gran mercado soñado. Ahí está ahora el caso adverso para el Kremlin, de las nuevas y verdaderas elecciones en Ucrania, donde el nuevo presidente Víctor Yutchenko es más proeuropeo que pro-gran-madre Rusia. En estas circunstancias V. Putin se ha opuesto radicalmente a todo diálogo que conceda la independencia a la república de Chechenia. En enero 2002 Putin prometió un Estado fuerte y un nuevo patriotismo ruso. El nacionalismo ruso se opone radicalmente a la secesión de la república chechena y justifica la "guerra contra estos terroristas". La Duma (cámara baja del parlamento) se opone a reducir las armas nucleares. Uno de los primeros actos de Putin fue confirmar y visitar el frente de guerra de Chechenia, lo cual le granjeó el apoyo de la población. Se unen así las dos reformas rusas.

Un editorial de El País califica como "golpe de mano" las medidas políticas y administrativas, muy poco democráticas, anunciadas por Putin luego de los sangrientos actos terroristas en la escuela de Beslan. Ya a mediados de septiembre Collin Powell había cuestionado estas medidas. "El plan prevé acabar con las elecciones directas de gobernadores o líderes regionales, y que estos sean designados por los respectivos parlamentos a propuesta del Kremlin. Sugiere también una reforma de la Duma en provecho de los grandes partidos, mediante un sistema único de elección proporcional que hará casi imposible la presencia de candidatos independientes de las regiones, que hasta ahora representaban hasta la mitad de la Cámara. El líder del Kremlin se ha adentrado en una peligrosa vía autoritaria, atacando a los medios de comunicación, azuzando sentimientos patrióticos, persiguiendo a grupos de oposición y a oligarquías financieras que hacen frente a su política o cercenando el poder regional como si así fuera posible exterminar el cáncer del terrorismo o de la corrupción. Se trata de un paso atrás, incluso de una regresión a modos autoritarios y un ataque frontal a regiones y repúblicas autónomas en pos de un Estado fuerte y centralizado, que casa mal con su estructura federal. Como ha dicho el último de los 
dirigentes soviéticos, Mijail Gorbachov, un gobierno no arregla sus problemas limitando los derechos de la ciudadanía".

"Tres semanas después de la carnicería en Beslan, V. Putin se decide a poner en obra el fortalecimiento del poder central de los ministerios de Seguridad, Defensa e Interior. Más de cuarenta proyectos de ley se presentan al Parlamento para luchar contra el terrorismo internacional. La Duma, dominada por el partido presidencial, Rusia Uni$\mathrm{da}$, ha adoptado el pasado miércoles una resolución que pide la consolidación de todas las estructuras de poder. Las medidas programadas organizan el mayor control de extranjeros, limitan la circulación de personas y prevén una censura de los medios de comunicación, en caso de crisis. Se constituye una especie de gobierno paralelo en todo el Cáucaso del Norte, desestabilizado por la guerra de Chechenia". (ECA, 2004; pp. 1029-1032)

En la reciente Asamblea General de Naciones Unidas (septiembre 2004) ha habido un intercambio diplomático de "preocupaciones" sobre las medidas tomadas por Putin, luego de los sucesos de Beslan. El Secretario de Estado, Colin Powell, ha discutido con S. Laurov las medidas propuestas para las elecciones de diputados en la Duma y el nombramiento de gobernadores en las Repúblicas Federadas. Laurov respondió: "Estas medidas se basarán en la Constitución de nuestro país, y continuaremos con la defensa de nuestros intereses legítimos a través de un diálogo amigable, la cooperación y la ayuda, más que por la confrontación. Se trata de reforzar la unidad del país y de su pueblo para luchar contra el terrorismo y garantizar una existencia segura y digna a nuestros ciudadanos, en libertad y democracia". (Le Monde, 24 de septiembre de 2004)

Estas eran las explicaciones que Bush pedirá a Putin en el foro Asia-Pacífico, noviembre 2004. Desde luego no es George W. Bush la persona más indicada para pedir explicaciones por estas medidas antidemocráticas, cuando en realidad no distan mucho de las medidas de control interno impuestas por el ministro de Justicia, John Ashcroft, luego del 11 septiembre, tal como aparece en la carta abierta de Norman Birbaum. Al mes siguiente será V. Putin quien le devuelve el bumerán a George W. Bush. "El presidente ruso, Vladimir Putin, acusó ayer indirectamente en Nueva Delhi a Estados Unidos de llevar a cabo una política exterior dictatorial y de provocar un aumento de la 
violencia que pone en peligro la paz y la democracia en Irak. "La dictadura en la política internacional nunca resolverá los problemas ni siquiera si (la dictadura) viene camuflada de bonitos discursos pseudodemocráticos; incluso los podrá empeorar". Las políticas "basadas en principios cuarteleros de un mundo unipolar parecen ser extremadamente peligrosas".

En esta visita a la India V. Putin lanzó un llamamiento conjunto a una mayor cooperación para reconstruir y estabilizar Irak. El unilateralismo ha incrementado el riesgo de que armas de destrucción masiva caigan en manos de terroristas, según Putin. Además acusó a Occidente por el doble rasero en cuestiones de terrorismo, persiguiendo por un lado a los fundamentalistas islámicos en Afganistán e Irak, mientras "dan refugio a terroristas" chechenos que piden la independencia de Rusia. "Dar cobijo y apoyo a terroristas, a sus cómplices y a sus promotores les sirve de justificación y les anima a cometer crímenes", aseguró el presidente ruso. "Putin considera la política estadounidense "dictatorial”. El País, 4 de diciembre de 2004)

$\mathrm{Al}$ interior de Rusia se están llevando a cabo simultáneamente las dos reformas mencionadas. V. Putin anunció el 17 de noviembre que Rusia iba a contar pronto con nuevos sistemas de armas nucleares que "no existen y no existirán en los próximos años en otras potencias nucleares. Seguimos con las investigaciones y ensayos de sistemas nucleares más modernos. Estoy seguro que en los próximos años ellos serán parte de nuestro equipo nuclear". De acuerdo a expertos, parece que se trata de misiles de 10.000 kilómetros de alcance, cuya velocidad le permite atravesar un escudo antibalístico. Pueden seguir operando hasta el año 2040. El presidente ruso ha indicado que la lucha contra el terrorismo, "una de las principales amenazas actuales", no debía impedir a Rusia proseguir el programa de rearme y modernización de sus fuerzas estratégicas. "Bastaría con que descuidáramos nuestra atención a estos componentes de nuestra defensa, que forman parte de nuestro escudo de misiles nucleares, para que nos encontremos confrontados a otras amenazas". Sin embargo, Putin no especifica cuáles son esas amenazas. Si Washington dice que "nosotros no vemos en esto nada nuevo" y si el Pentágono agrega que su escudo antibalístico no está concebido para enfrentar ataques de largo alcance provenientes de China o de Rusia, ¿quién es el destinatario? ("Putin 
promete a su armada nuevas armas nucleares". Le Monde, 18 de noviembre 2004. "Nostalgia a la rusa". Le Monde 18 de noviembre 2004)

Con fecha 6 de diciembre, La Prensa Gráfica nos da una impresionante noticia: " 25 mil árabes listos para ataques suicidas. Miles se reclutan como kamikazes en Teherán para Irak". Irán es considerado el "gigante musulmán" y cuenta con el ejército islámico más poderoso de la región. El presidente pakistaní Pervez Musharraf estimó ayer que el mundo es "menos seguro" desde la invasión a Irak por tropas estadounidenses y británicas. El se opuso a la invasión de Irak, pero agregó que "los soldados estadounidenses no deberían retirarse de Irak ahora porque se crearían aún mayores problemas". "Palestina, ese es el corazón de todos los problemas". (p. 42). ¿Dónde se inicia el terrorismo?.

\section{La crisis del multilateralismo}

En la secuencia de testimonios antes citados (A. Schelesinger, N. Birbaum, A. Touraine, M. Naim, B. Clinton, entre otros) se hace referencia al unilateralismo de la administración Bush. Este unilateralismo presenta las características de un imperialismo mesiánico, reconocido como la "Pax Americana". En el foro económico de Davos en Nueva York, febrero 2002, ante los restos calcinados de las torres gemelas el secretario de Estado, Colin Powell, hace profesión de su unilateralismo: "Nosotros creemos en el multilateralismo. Pero cuando se trata de una cuestión de principios y cuando la comunidad internacional no está de acuerdo con nosotros, no dejamos de hacer lo que estimamos justo y en nuestro interés, aunque algunos de nuestros amigos no estén de acuerdo". En forma similar se expresará el presidente George W. Bush, quien piensa dedicar el resto de su existencia presidencial a la lucha contra el terrorismo: "La historia nos ha dado la oportunidad de defender la libertad y de combatir la tiranía, y esto es lo que nuestro país hará... Tal vez algunos se cansarán. Otros, tal vez, se fatigarán ante nuestros esfuerzos por la libertad. No así yo, ni mi gobierno, ni nuestro país”. (Le Monde, 9 de febrero de 2002)

Cuando ya estalla la guerra de Irak, la revista $E C A$ dedica su editorial de mayo 2003 a la "Nueva fase del imperialismo de Estados Unidos". El proyecto imperial de EEUU descansa sobre dos elementos claves: la fuerza militar y el poder económico. Está convencido de que puede hacer aquello que se proponga sin dar cuenta a nadie. De

Bush Il y la crisis del mulfilateralismo 
su poder económico y militar y de la impunidad Estados Unidos deriva su pretendida superioridad moral, lo cual le daría derecho a hacer lo que se proponga por el bien de los demás. La pretendida superioridad moral les autoriza a imponer su voluntad sobre los demás pueblos y naciones. "Según esta lógica, aquello que es bueno para Estados Unidos, también es bueno para el resto de la humanidad, y quienes se oponen a él están contra él, es decir, son las fuerzas del mal. En la historia del imperialismo el origen de esa superioridad es la providencia divina que habría dado a los imperios la misión de regenerar el mundo".

Si en el área del libre comercio internacional, J. Stiglitz utiliza el calificativo de hipocresía, en el campo militar y geopolítico, "la mentira está al servicio del imperio". "Los imperios se construyen sobre la mentira y las víctimas y el imperio estadounidense no es la excepción. Imperio, verdad y vida son irreconciliables". Washington y Londres mienten para justificar la invasión de Irak, y las cadenas transnacionales de información hicieron creíble la mentira al presentar a Estados Unidos como la víctima de los "estados que se encuentran fuera de la ley". Bush también dijo que el Consejo de Seguridad era un irresponsable y que ellos hicieron lo que había que hacer. "La democracia prometida, en consecuencia, es otra gran mentira", porque se impone con ejércitos extranjeros de ocupación. "Las primeras concesiones otorgadas por Estados Unidos para hacer negocio con el petróleo y la reconstrucción de Irak no son más que un reparto del botín con el cual se lucrarán, en primer lugar, las transnacionales vinculadas al gobierno de Washington y luego aquellas otras relacionadas con los gobiernos que participaron en la invasión. Quienes rechazaron la invasión han sido excluidos del reparto, al menos hasta ahora. Las ventajas económicas y políticas de estar del lado de los vencedores y del imperio son evidentes. No obstante, no hay que olvidar que esas ganancias se hacen con la destrucción y la muerte".

Sin embargo, hay razones para la esperanza. "La invasión de Irak levantó una ola mundial de protestas. El avance del imperialismo estadounidense logró unir y revitalizar las fuerzas que luchaban por un mundo mejor, más equitativo y humano, las cuales parecían estar claudicando de forma definitiva ante el capitalismo neoliberal”. Nace así el Foro Social Mundial de Porto Alegre, que congrega a los inconformes del Norte y del Sur frente a la actual globalización. "La 
omnipotencia imperial ha devuelto a la humanidad el deseo de luchar por un mundo mejor, contrario al que se pretende imponer por la fuerza. La utopía recobra así su lugar en las aspiraciones de la humanidad y fundamenta una esperanza renovada y vigorosa”... (ECA, 2003; pp. 369-384)

A final de año nos llega un comunicado de la Asamblea Global Anti-Guerra, que se hará presente en el Foro Social de Porto Alegre, celebrado entre el 26 y el 31 de enero de 2009. "La victoria de George W. Bush en las recientes elecciones de los Estados Unidos le han dado capital político para, según sus propias palabras, "avanzar a todo vapor", empezando por el bombardeo de Fallujah. El Secretario de Estado, Colin Powell, reforzó esta idea declarando que Bush continuaría sosteniendo su "política externa intervencionista y agresiva", agregando que actuaría sólo en caso necesario. Esta política exterior pondrá al Medio Oriente como prioridad. Es un momento crítico para la paz, la justicia y el movimiento anti-guerra en todo el mundo. Con el régimen Bush más dispuesto a dominar el mundo empezando por el Medio Oriente, el campo de batalla de Irak y Palestina se transforman en las prioridades del movimiento. Los movimientos globales contra la guerra necesitan unirse y construir una resistencia global más fuerte y más organizada contra la globalización corporativa y el imperialismo norteamericano, forjando vínculos más fuertes con los movimientos de la región". A continuación viene la propuesta que se presentará en el foro de Porto Alegre. (Focus on the Global South. Asamblea Global Anti-Guerra. 24 de diciembre 2004)

El enfrentamiento anti-guerra ya se venía y se sigue dando al interior de la ONU entre la administración Bush y Kofi Annan. En la $58^{a}$ conferencia de Naciones Unidas Kofi Annan cuestiona la guerra preventiva defendida por Estados Unidos. "Desde la fundación de esta institución los Estados han procurado enfrentar las amenazas a la paz por medio de la contención y disuasión basadas en un sistema de seguridad colectiva de acuerdo a la Carta de Naciones Unidas. El artículo 51 prevé que todos los Estados, si son atacados, tienen el derecho de defenderse. Hasta ahora estaba admitido que cuando los Estados de exceden y deciden recurrir a la fuerza para responder a graves amenazas a la seguridad y a la paz internacional, necesitan contar con la legitimidad que sólo pueden procurar las Naciones Unidas. 
Ahora, algunos dicen que esta teoría no es sostenible cuando un ataque armado de destrucción masiva puede lanzarse en cualquier momento, sin previo aviso o por un grupo clandestino. Los Estados, arguyen, tienen el derecho y la obligación de utilizar la fuerza de manera preventiva, incluso sobre el territorio de otros Estados y aun cuando el sistema de armas utilizables en el ataque estén en proceso de fabricación. Esta lógica representa un cambio fundamental respecto a los principios sobre los que reposaba la paz y la estabilidad del mundo desde hace cincuenta y ocho años, aunque haya sido de manera imperfecta. Lo que me inquieta es que, si se adopta este principio, pudiera crear precedentes que multiplicarían el recurso a una fuerza unilateral y sin fundamento jurídico, con o sin ninguna justificación". ("La $58^{a}$ reunión de la ONU: Reformas y contrarreformas." Realidad 2003; p. 735)

El deseo de Kofi Annan era llevar adelante el programa de reformas que se habían planteado ya en la cumbre del milenio. Algunas de las reformas quedan reflejadas en las siguientes preguntas. "¿Para qué sirven las Naciones Unidas si no logra que se respeten sus resoluciones?. ¿Cuál es la representatividad del Consejo de Seguridad y cuáles los criterios que le permitan decidir el uso de la fuerza?. ¿Hay que conservar el 'derecho al veto'? ¿Habrá que pensar en trasladar la sede de la ONU fuera de Nueva York? ¿ Cuál es la responsabilidad de la comunidad internacional cuando un Estado no protege a sus ciudadanos?”. (Ibídem, p. 741) Esta era parte de la agenda que se debía discutir y que, por presión de la delegación de Estados Unidos, fue a parar a la papelera de reciclaje. Naciones Unidas, que no había autorizado la guerra de Irak, ahora debía legitimar la invasión y convertir una fuerza de ocupación en una fuerza multinacional autorizada por la ONU. En esa ocasión se dijo que "todos jugaron al póquer del mentiroso". (Ibidem; pp. 748-750)

Una de la preguntas era: ¿hay que conservar el derecho al veto?. Con fecha 14 de octubre 2003, en plena sesión de la asamblea de Naciones Unidas, Siria solicita al Consejo de Seguridad, en nombre de la Liga Árabe, que se condene la construcción de parte de Israel del muro de seguridad en Cisjordania. El texto juzgaba que este muro "era ilegal de acuerdo a las normas del derecho internacional". Diez miembros del Consejo de Seguridad avalan la condena del muro de 
Cisjordania. Pero John Negroponte, delegado de EE.UU., impone su veto, "porque el texto no es equilibrado", y el muro sigue su construcción. ¿De qué sirve el Consejo de Seguridad si la condena avalada por el "voto" de diez de sus miembros queda anulada por el "veto" del representante de un país que, al igual que Israel, se destaca por burlar tradicionalmente las decisiones de las Naciones Unidas?.

El unilateralismo de la administración Bush se repite en la segunda parte de la misma historia. Con fecha 21 de octubre de 2003, la Asamblea General de la ONU aprobó detener la construcción del "muro de seguridad", con una aplastante mayoría de 144 votos a favor, cuatro en contra (EE.UU., Israel, Islas Marshall y Micronesia) y 11 abstenciones. Como las resoluciones de la Asamblea General manifiestan sólo la voluntad de la comunidad internacional, el "muro" sigue su curso. El 8 de diciembre 2003 la Asamblea General de la ONU traslada su solicitud a la Corte Internacional de Justicia que, luego de las audiencias tenidas en febrero 2004, declara el muro ilegal de acuerdo a la noción de "territorios ocupados". Como la resolución de la Corte Internacional de Justicia no es vinculante, el "muro de la vergüenza" sigue su curso, sin tomar para nada en cuenta el "valor moral" de la sentencia de la Corte, como dijo Kofi Annan.

Por lo que atañe a la Corte Penal Internacional, esta ha sido ratificada por 94 de los 191 países miembros de la ONU; sólo cinco países, de los quince miembros del Consejo de Seguridad, han ratificado sus estatutos y tres de los cinco miembros permanentes y con poder de veto tampoco los han ratificado: Estados Unidos, Rusia y China. ¿Por qué esos tres países no ratifican esos estatutos si la Corte Penal Internacional no será retroactiva, aplicándose sólo a aquellos delitos cometidos después del $1^{\circ}$ de julio 2002? ¿Qué seguridad nos puede dar semejante Consejo de Seguridad, si tres de sus miembros miran con recelo las sentencias que pueda dar una Corte Internacional?. En el presente año 2005 se han propuesto realizar 101 reformas dentro de la ONU, a comenzar por el Consejo de Seguridad conformado por 24 miembros.

En la reunión más reciente de Naciones Unidas, llevada a cabo el 20 de septiembre de 2004, Kofi Annan volvió a decir que la guerra de Irak era "ilegal" y la administración Bush, que no admite acusaciones, tampoco perdona. Dado que en pasados años un hijo de Annan se 
habría lucrado, o cuando menos, habría permitido que otros se lucraran con el programa "Petróleo por alimentos" en Irak, ahora algunos congresistas han pedido su retiro de la ONU y alguno su encarcelamiento por corrupción. En esta reunión de la ONU "La Unión Europea expresa su apoyo a Annan frente al acoso en EEUU”. (El Pais, 18 de diciembre 2004) Kofi Annan había dicho que "el Estado de derecho está en peligro en las cuatro esquinas del mundo. Ningún país está por encima de la ley. Los gobiernos que proclaman la primacía del derecho en su país, deben respetar la legalidad fuera de casa; los que insisten en que el derecho prevalezca fuera, deben asegurar su preeminencia dentro. Quienes pretenden conferir la legalidad deben también encarnarla; quienes invocan el derecho internacional deben también someterse al mismo". (Le Monde, 22 de septiembre 2004)

El ministro de Asuntos Exteriores de Holanda, Bernard Bot, presidente de turno de la Asamblea General, dio el apoyo de la Unión Europea a Annan. La Unión Europea está en pleno acuerdo con él. "El terrorismo no debe utilizarse como excusa para violar los derechos humanos. Los Estados deben asegurar que todos los medios que se utilicen para combatir el terrorismo sean conformes al marco del derecho internacional". Bot reafirmó la importancia de la Corte Penal Internacional para la Unión Europea, "a fin de poner un límite a la impunidad y reforzar el Estado de derecho en el mundo". La Unión Europea "se esforzará" para que la mayoría de países ratifiquen el tratado de Roma, 1998, que creó dicha Corte Penal Internacional, cuya jurisdicción ahora sólo reconocen 94 países. Estados Unidos rechaza que sus ciudadanos puedan ser entregados a este tribunal y se ha negado a ratificar los estatutos que Bill Clinton había aprobado el último día de su gobierno". La última Asamblea General de Naciones Unidas sirvió para ampliar el distanciamiento de la Unión Europea, en general, con el Gobierno de los Estados Unidos, que sólo se escucha a sí mismo. (Le Monde, 22 de septiembre 2004)

Del 6 al 17 de diciembre se reunieron en Buenos Aires alrededor de seis mil representantes de 180 países, ONG y otras instituciones, para discutir la puesta en marcha del protocolo de Kyoto y el papel de los países en desarrollo en la lucha contra el gas de efecto invernadero. Con la adhesión de Rusia el pasado 18 de noviembre, ya son 55 los países que han ratificado el protocolo de Kyoto, que representan más del 55\% de la emisión de gas de efecto invernadero. Una vez 
más, el actual gobierno de los Estados Unidos, el mayor contaminante, se niega a firmar dicho protocolo renovando los desplantes hechos en la reunión del G-7 en Génova, julio 2001, y en la cumbre de Johannesburgo, agosto 2002. El gobierno de los Estados Unidos asiste a la presente reunión porque un anterior Gobierno había firmado la Convención del Clima de la ONU, que entró en vigor en 1994. Algunos países en desarrollo, liderados por la India, considerando que la aplicación de normas protectoras del medio ambiente puede frenar su crecimiento económico, solicitan que los países desarrollados les ayuden técnica y financieramente a revertir su degradación ambiental. En la cumbre de Johannesburgo, Alemania y Francia se habían ofrecido a aportar estas ayudas de manera que el $15 \%$ de la energía mundial fuera energía limpia, eólica, solar. Pero la administración Bush no se compromete con pacto alguno que comprometa su unilateralismo, tal como lo dijo Bill Clinton. (Clima: el tratado de Kyoto se aplicará sin los Estados Unidos". Le Figaro, 6 de diciembre de 2004)

Una noticia de última hora viene a resaltar el unilateralismo ideológico de la administración Bush: "Renunciará presidente del Banco Mundial". Se trata de James Wolfensohn que, luego de dos décadas al frente del BM, prevé que dejará su cargo este año. La decisión estaba condicionada al resultado de las elecciones de Estados Unidos. Según medios de comunicación ha habido muchas tensiones entre la actual administración Buhs, reelecto, y Wolfensohn con motivo de la financiación y el empleo de las ayudas del BM. "Bajo su égida, la institución que más créditos concede en el mundo para proyectos de ayuda al desarrollo se concentró sobre todo en la lucha contra la pobreza y la corrupción, y en proyectos humanitarios de educación, asistencia a discapacitados, prevención del sida y protección del medio ambiente". (La Prensa Gráfica, 3 de enero 2005)

Seguramente la persona no es la institución, ni la institución es la persona, es decir, que Wolfensohn ha intentado humanizar la institución del Banco Mundial, que ha contado con economistas como J. Stiglitz y ahora Nicolas Stern. El discurso de Wolfensohn "La otra crisis", pronunciado el 6 de octubre de 1998, con ocasión de la crisis financiera (ECA 1998; pp. 1003-1009) pretende dar un carácter más humanitario y más dialogante con los países a todos los programas de asistencia económica-social. Por el otro lado, no son muy claras las 
intenciones de la Comisión Meltzer, organizada por el Congreso de EE.UU., de reducir las actividades del FMI y BM, marzo 2000, a los que fueran sus objetivos fundacionales en 1945 . Se pretende sacar del paraguas del FMI y BM a muchos países que pudieran buscar su financiamiento en el mercado de capitales privados (en su mayoría norteamericanos), antes llamados capitales golondrinas y ahora 'capitales tsunamis', por la intensidad y la imprevisión de sus llegadas y salidas. En la cumbre del FMI y el Banco Mundial, celebrada en Praga en septiembre de 2001, los presidentes de ambas instituciones, Horst Kohler y Wolfensohn, respectivamente, criticaron la reducción de las ayudas oficiales a los países pobres. "Las ayudas de Occidente al tercer mundo no han hecho más que menguar en la última década y esto es un crimen". Wolfensohn piensa que la gran misión del BM es la lucha contra la pobreza, y no comulga con la ideología de George W. Bush, que la libertad política y económica son la mejor medicina para combatir la pobreza.

Esta última cita y este enfrentamiento son un símbolo de lo que promete ser el presente año 2005. La administración Bush, de línea más dura, ha comenzado a anunciar su buena noticia: el problema número uno del mundo es la lucha contra el terrorismo internacional. No hay el menor signo de arrepentimiento por la guerra de Irak y tal vez le sigan Irán y Corea del Norte. El problema mayor es que la lucha contra las "amenazas duras" (armas de destrucción masiva...) nos lleve a olvidar el combate contra las "amenazas blandas" (pobreza, pandemias, degradación ambiental...), que son la semilla del terrorismo. El temor mayor es que la lucha contra el terrorismo genere más terrorismo; una guerra perdida de antemano. 